\title{
A Comparison Study on the Survival Characteristics of Big Old Sophora japonica and Zelkova serrata Called 'Goe'
}

\author{
Jae-Hyun Rho ${ }^{1}$, Sang Yup Han ${ }^{2 *}$, and Sang Beom Kim ${ }^{3}$ \\ ${ }^{1}$ Professor, Department of Landscape Architecture, Woosuk University, Wanju 55338, Korea \\ ${ }^{2}$ Head of Team, Landscaping Team, Hanbek Construction, Jeonju 54856, Korea \\ ${ }^{3}$ Professor, Department of Civil Engineering and Landscape Architecture, Koguryeo College, Naju 58280, Korea
}

\section{ABSTRACT}

With the aim of accumulating data that can be used to infer the basis for the acculturation of trees called 'Goe,' this study aims to identify the survival status of the pagoda and zelkova trees known as 'Goe' trees by comparing and analyzing the status of pagoda trees (Sophora japonica) and zelkova tree (Zelkova serrata) designated as a protected tree in Korea. The results of this study are as follows;

Zelkova serrata designated as a protected tree grows the most, with 2,147 trees (29.4\%) in Cheonnam, followed by Chungnam (16.5\%) and Gyeongbuk (14.4\%). However, Sophora japonica showed a different result from zelkova Serrata as the total number of 210 Sophora japonica (55.7\%) in Gyeongbuk and Daegu is much larger than that of zelkova Serrata. As a result, in the Yeongnam region, where the Confucianism of Yeongnam was actively practiced, the existence of Sophora japonica is much larger than that of the Zelkova Serrata, which is not a coincidence, and it is difficult to determine it only based on their flora and planting distribution. Results of comparing protected trees of Sophora japonica and Zelkova Serratá showed that the average age of Zelkova Serrata wass 289 years, while that of Sophora japonica was 302 years, and that the average height of Zelkova Serrata wass $18 \mathrm{~m}$, which is higher than the height of $16 \mathrm{~m}$ of Sophora japonica. The average diameter at breast height of Zelkova Serrata was $398 \mathrm{~cm}$ and that of Sophora japonica was $314 \mathrm{~cm}$, which indicates that Zelkova Serrata is relatively big. Therefore, it can be assumed that Zelkova Serrata has a larger growth potential than Sophora japonica, and the possibility of growth as a big tree is also high, but it seems that the explanation that "they are relatively long-lived" is not clearly determined.

Keywords: acculturation, Goemok, old big trees, Pagoda tree, protected trees, Zelkova tree

\section{Introduction}

Our ancestors considered the symbolism and meaning of every single flower and tree when planting them on their garden (Huh, 2002). However, it is difficult to say that the cultural icon of certain species of trees such as their symbolism and implication is always the same. Kang (2014) introduced cases of planting trees such as Ginkgo biloba, Sophora japonica and Zelkova serrata as a typical case of acculturation found in China and Korea and emphasized that Sophora japonica and Zelkova serrata, targets of this study, are not only an excellent landscape tree but also are considered as an invaluable tree in understanding the history and culture of China and Korea. Out of them, Sophora japonica introduced from China was considered as a 'symbolic tree' of Confucianism, being called the tree of scholars. However, Sophora japonica is one of the trees that have been wrongly understood and used like Platycladus orientalis, and the first Chinese character (槐, Goe) of Sophora japonica is understood as Zelkova serrata, a tree of the Ulmaceae family, as Zelkova serrata is also called 'Goemok (槐木).' According to the Standard Korean

Received: December 18, 2019, Revised: January 13, 2020, Accepted: February 5, 2020

First author: Jae-Hyun Rho, orchid116@naver.com, (1) https://orcid.org/0000-0002-3690-7144

*Corresponding author: Sang Yup Han, hansy03@hanmail.net, (10) https://orcid.org/0000-0002-8300-0799 
Language Dictionary published by the National Institute of Korean Language (2000), the first plant stated under the word 'Goemok' is Sophora japonica and the second plant is Zelkova serrata, but they are categorized into two different genera - 'Sophora' and 'Zeltova' respectively.

Kang (2015) said that as Sophora japonica was introduced to Korea, it was perceived differently - on the one hand as Sophora japonica and on the other hand as Zelkova serrata - but also added that no record is available showing that Sophora japonica was accepted as Zelkova serrata. As he pointed out, since the word used to call Sophora japonica in the Chinese character was 'Goe'- the same character used to call Zelkova serrata, - the word 'Goemok' in ancient poetry and prose can be interpreted as Sophora japonica or Zelkova serrata and thus it can be easily predicted that this might cause many confusions. 'Goe' in the word '槐花' calls all the species of Sophora both in China and Korea, but the plant-sociologically view that it referred to Zelkova serrata rather than Sophora japonica is very convincing (Kim, 2013). Since very few studies have been conducted on the acculturation of trees in dendrology or landscape architecture, it is necessary to search a methodology for approaching the essence of the identify of 'Goe' through a more empirical method.

Viewing that Sophora japonica is native to China and that its life is shorter than that of Zelkova serrata seems to be a prejudice towards only a few old big trees designated as a natural monument. It is generally accepted that there is no known habitat of Sophora japonica in Korea and that it is also difficult to buy it in Korea, while people think that there are natural habitats of Zelkova serrata in Korea and that it also grows fast and lives longer than Sophora japonica (Han and Rho, 2019). However, this view has not been empirically confirmed. Sophora japonica is one of the five species of big trees in Korea along with Zelkova serrata, Celtis sinensis, Ginkgo biloba and Salix chaenomeloides, about 30 Sophora japonica trees aged between 500 and 1,000 are designated as an old big tree and are protected. Therefore, it will be very useful to monitor their growth.

Against this backdrop, this study aimed to analyze and compare the remaining characteristics of Sophora japonica and Zelkova serrata called 'Goemok' and to accumulate data that can be used to infer grounds for the acculturation of Sophora japonica and Zelkova serrata.

\section{Research Methods}

\section{Definition of terms}

\section{A protected tree}

A protected tree is a tree that is protected for its reproduction, the preservation of scenic beauty and academic research and includes big trees that are worth preserving and protecting for proliferation among old trees, big trees and rare trees 1 ). The term used in this study was defined based on the operational definition in a broad sense as "trees that are designated as a natural monument (plant) by the Cultural Heritage Protection Act and are designated as a protected tree by the Forest Protection Act."

\section{Acculturation}

Acculturation is a phenomenon in which two different cultures create a culture that is different from either of them or both of them through continuous and direct contact and its concept is different from assimilation, a process in which one of the two adapts itself to the host culture (Berry, 1997). Choi (2013) said that being a bicultural or multicultural person is a result of adaptation. The dictionary definition of acculturation in cultural anthropology is (1) a process in which a part of or the whole of a group is adopted by one group or both of the two groups and contact between different cultural groups leads to the acquisition of a new type of culture, or (2) a process in which two autonomous cultural systems or more contact continuously with each other and all the systems change (http://www.doopedia.co.kr).

1) The designation and management of protected trees are subject to Article 13 of the Forest Protection Act, and some local governments enacted ordinances to systematically designate, protect and manage protected trees. The protected tree system has been implemented according to Article 67 and 70 of the Forest Act, and protected trees are designated by each mayor, Do governor or the head of a regional forest office. 


\section{Subjects and scope}

The scope of this study was limited to South Korea and the subjects of this study were limited to protected trees designated by the central government or metropolitan and basic local governments including si(city), do(province), gun(county) and $g u$ (borough) among Sophora japonica and Zelkova serrata trees called 'Goemok.'

\section{Survey and analysis methods}

A complete enumeration was conducted to survey the number of Sophora japonica and Zelkova serrata trees that live in Korea, are designated as a protected tree in Korea and are recorded in documents. Based on the operational definition of a protected tree used in this study, all the natural monuments among state-designated cultural properties and protected trees designated by si, gun and $g u$ offices ${ }^{2)}$ were comprehensively surveyed. Information on natural monuments was collected from the website of the Cultural Heritage Administration (www.cha.go.kr) in October, 2018. When the number of Zelkova serrata and Sophora japonica trees did not surpass $20 \%$ of the total number of designated trees, they were excluded from the subjects of this study. For instance, like trees in line in Cheongcheon-ri, Muan-gun (designated as Natural Monument No. 89), the case where only three trees out of a total of 89 protected trees were designated as Zelkova serrata was excluded. Based on these criteria, a total of five cases on Sophora japonica trees designated as natural monuments were surveyed and the items surveyed through literature review include protected Zelkova serrata and Sophora japonica trees, designation number, serial number, major species, designated date, location, height, age and diameter at breast height. Frequency analysis was conducted on the surveyed data using the Excel program.

2) According to Article 13 (Designation and Management of Protected trees) of the Forest Protection Act, each Mayor, Do Governor or the head of a regional forest office shall designate a trees, which is an old tree, a great tree, or a rare tree and which requires special protection, as a protected tree and safeguard it at the place there it is.

\section{Results and Discussion}

\section{Acculturation of Sophora japonica and Zelkova serrata}

Zhouli Zhushu that recorded the administrative law of the Zhou dynasty in Ancient China stated that three Sophora japonica trees were planted in the outer control office within the palace and were recognized as the place of the Three Ducal Ministers. The inner control office within the palace was a place where the king had meetings with the Three Ducal Ministers, top officials, bureaucrats and aristocrats. In particular, in the places for the premier, the first and second vice-premiers, Sophora japonica trees were planted to mark the places as first-class seats(Han, 2019). The character 'Goe' means all the species of Sophora both in China and Korea, but one thing clear is that from the plant-sociologically perspective the trees referred to 'Goe' in the word '槐花' mean Zelkova serrata rather than Sophora japonica at least in Korea (Kim, 2013). Although Zelkova serrata trees are one of the tree species that represent Korea, there is no separate Chinese character that means Zelkova serrata on the Korean Peninsula unlike China, and in the process of using 'Goe (槐)' that means Sophora japonica the character seems to be mistranslated. There are numerous cases that mistranslated Sophora japonica as Zelkova serrata, and especially mistranslation cases observed in key documents such as the Veritable Records of the Joseon Dynasty and the Korean Literary Collections are serious. These mistranslation cases show not just differences in the name of trees, but they can cause confusions to related history and culture and even thoughts and philosophies thoroughly. The origin of the Korean names of Sophora japonica as Zelkova serrata are not identical, but from a plant-sociological perspectively they are two different species considering their origin, their conditions of inhabitation and the framework of their life (Han, 2019).

Han and Rho (2019) and Rho et al. (2019) surveyed the species and status of Goemok plantings in Goejeongs, a kind of pavilion, for the purpose of discussing how they were perceived and used and provided grounds for confirming the clear tendency that Zelkova serrata was alternatively planted instead of Sophora japonica in non-Yeongnam re- 
gions in Korea. That is, Sophora japonica or Zelkova serrata trees that were planted in the early stage of creating gardens started to wither and withered to death due to aging, poor environmental adaptation and poor management and it can be assumed that Zelkova serrata trees could grow relatively more and were more accessible, which was pointed out as a major variable for acculturation. In addition, remaining Goemok trees in Goejeong pavillions were Zelkova serrata and Sophora japonica and it was also found that those that represent Goemok across the country were mostly Zelkova serrata. This case can be recognized as some kind of acculturation, but this does not mean that complete acculturation was achieved by region, which is proved by the clear manifestation of the fact that Sophora japonica was perceived as Goemok in the Yeongnam region unlike non-Yeongnam regions. These results indicate that Goejeong pavillions were distributed across the country but unlike the tendency of remaining Zelkova serrata trees they were concentrated in the Yeongnam region. Based on this, it can be assumed that the Goemok culture of Sophora japonica is in line with the Neo-Confuciansim culture in the Yeongnam region.

\section{Status of designated Goemok trees based on the status of protected trees}

\section{Status of the designation and distribution of protected trees}

A total of 13,659 trees designated as protected trees were analyzed to identify their species, and the share of Zelkova serrata was overwhelmingly high (7,281 cases, 53.3\%), followed by Pinus densiflora (1,530 cases, 11.2\%), Celtis sinensis (1,346 cases, 9.9\%), Ginkgo biloba (778 cases, 5.7\%), Salix koreensis (492 cases, 3.6\%), Sophora japonica (372 cases, 2.7\%), Juniperus chinensis (227 cases, $1.7 \%)$ and others (1,633 cases, $11.96 \%$; Table 1$)$. The ratio of Zelkova serrata to Sophora japonica was 53.3 : 2.7, indicating that the share of Zelkova serrata was relatively very high. This can be attributed to the following three aspects. "First, Zelkova serrata has a higher potential to

Table 1. Species analysis of protected tress(unit: case)

\begin{tabular}{|c|c|c|c|c|c|c|c|c|c|}
\hline Region & Sum & $\mathrm{Ze}$ & $\mathrm{Pd}$ & $\mathrm{Cs}$ & $\mathrm{Gb}$ & $\mathrm{Sk}$ & $\mathrm{Sj}$ & $\mathrm{Jc}$ & Etc. \\
\hline Seoul & 212 & 103 & 8 & - & 48 & - & 18 & 14 & 21 \\
\hline Busan & 97 & 13 & 24 & 32 & 2 & & 5 & & 21 \\
\hline Daegu & 306 & 106 & 23 & 38 & 22 & 12 & 23 & 1 & 81 \\
\hline Incheon & 116 & 58 & 11 & 6 & 21 & - & 6 & 5 & 9 \\
\hline Gwangju & 77 & 38 & 3 & 14 & 5 & 8 & 2 & - & 7 \\
\hline Daejeon & 125 & 91 & 12 & 2 & 6 & 9 & 2 & 1 & 2 \\
\hline Ulsan & 64 & 7 & 14 & 9 & 1 & - & 7 & 1 & 25 \\
\hline Gyeonggi & 1,078 & 617 & 31 & 10 & 208 & 2 & 36 & 99 & 75 \\
\hline Gangwon & 718 & 205 & 172 & 4 & 41 & - & 3 & 10 & 283 \\
\hline Chungbuk & 1,223 & 685 & 278 & 16 & 65 & 30 & 7 & 22 & 120 \\
\hline Chungnam & 1,777 & 1,203 & 83 & 94 & 101 & 105 & 25 & 20 & 146 \\
\hline Jeonbuk & 638 & 443 & 51 & 47 & 35 & 21 & 5 & 2 & 34 \\
\hline Jeonnam & 4,051 & 2,143 & 462 & 758 & 82 & 182 & 30 & 10 & 384 \\
\hline Gyeongbuk & 2,026 & 1,048 & 250 & 78 & 86 & 121 & 186 & 37 & 220 \\
\hline Gyeongnam & 911 & 474 & 74 & 134 & 46 & & 16 & 2 & 165 \\
\hline Jeju & 162 & - & 33 & 102 & - & - & 1 & - & 26 \\
\hline Sejong & 78 & 47 & 1 & 2 & 9 & 2 & - & 3 & 14 \\
\hline sub total & 13,659 & 7,281 & 1,530 & 1,346 & 778 & 492 & 372 & 227 & 1,633 \\
\hline
\end{tabular}

Note. $\mathrm{Ze}=$ Zelkova serrata $; \mathrm{Pd}=$ Pinus densiflora $; \mathrm{Cs}=$ Celtis sinensis $; \mathrm{Gb}=$ Ginkgo biloba $; \mathrm{Sk}=$ Salix koreensis $; \mathrm{Sj}=$ Sophora japonica $;$ $\mathrm{Jc}=$ Juniperus chinensis. 
grow into an old big tree compared to Sophora japonica. Second, since Sophora japonica is not native in Korea, its environmental adaptability is lower than that of Zelkova serrata and tended to wither to death even before they reached their maximum age. Third, compared to Sophora japonica, the frequency of planting Zelkova serrata trees and the number of Zelkova serrata trees was overwhelmingly high 3$)$."

The status of Zelkova serrata and Sophora japonica trees designated as an old big tree by species was surveyed as follows.

\section{(1) Sophora japonica}

A total of 5 cases $(1.12 \%)$ of Sophora japonica trees were designated as a natural monument, and out of them the following four cases were single trees: No. 315 in Shinhyeon-dong, Incheon; No. 317 in Samwol-ri, Dangjin; No. 318 in Yuktong-ri, wolseong; No. 319 in Chilbuk-myeon, Haman; and No. 319 in Yeongdong-ri, Haman. Only one case is designated as a group (8 trees) - No. 472 in Changdeokgung Palace. One of provincial monuments is the Sophora japonica tree in Haemieupseong, Seosan (Chungnam Provincial Monument No. 172).

\section{(2) Zelkova serrata}

A total of 19 cases (4.27\%) of Zelkova serrata trees were designated as a natural monument including the long-leaf Zelkova serrata tree in Dogye-ri, Samcheok (No. 95). Excluding 3 cases, in the rest cases single trees were designated as a protected tree. Natural Monument No. 108 in Daedong-myeon, Hampyeong is a group mixed with three different species including Celtis sinensis, Zelkova serrata and Campinus Tschonoskii MAX. Natural Monument No. 161 in Seongeup-ri, Jeju is a group mixed with different species such as Zelkova serrata and Celtis sinensis, and there was only one Zelkova serrata tree in the group.

3) Rho et al. (2019) analyzed the age of trees that remained in Goejeongs by species, and reported that the average age of Sophora japonica and Zelkova serrata trees was 226.4 and 315.6 respectively. In addition, the average height of Sophora japonica and Zelkova serrata trees was $11.7 \mathrm{~m}$ and $16.6 \mathrm{~m}$ respectively, and their average diameter at breast height was $237.8 \mathrm{~cm}$ and $366.1 \mathrm{~cm}$ respectively. In terms of their height, age and diameter at breast height, the results of Zelkova serrata trees was much higher than that of Sophora japonica trees, indicating that Zelkova serrata trees were old big trees.
In addition, Natural Monument No. 382 in Oga-ri, Goesan is composed of two Zelkova serrata trees in the upper and lower part of the hill respectively. A total of 42 Zelkova serrata trees are designated as a natural monument across the country.

According to Lee (1986), Zelkova serrata trees can grow on the Korean Peninsula in regions where their mean minimum temperature in January is higher than $-14^{\circ} \mathrm{C}$ and their warmth index ranges between 85 and 100. Except Pyeongan-do and the inner area of Hamgyeong-do centering on the Kaema Plateau, Zelkova serrata trees are evenly distributed across the country. Based on this, it seems fair to say that the entire regions of South Korea can be recognized as the flora of Zelkova serrata.

\section{Regions of remained protected Sophora japonica and Zelkova serrata trees}

The location of Zelkova serrata trees designated as a natural monument was analyzed by region as shown in Fig. 1. The number of Zelkova serrata trees designated as a natural monument in Jeonnam and Gyeongbuk was the highest (4 respectively), followed by Jeonbuk (3), Gyeongnam and Gangwon (2 repectively), and Daejeon, Gyeonggi, Chungbuk and Jeju (1 respectively), showing a relatively even distribution. However, there was only one Sophora japonica tree each in Seoul, Gyeonggi, Chungnam, Gyeongbuk and Gyeongnam.

The distribution of Zelkova serrata and Sophora japonica trees including natural monuments and protected trees was analyzed, and out of 7,300 trees, a total of 2,147 trees (29.4\%) were found in Jeonnam showing the highest remaining rate, followed by Chungnam (1,203 trees, 16.5\%), Gyeongbuk (1,052 trees, 14.4\%), Chungbuk (686 trees, 9.4\%), Gyeonggi (618 trees, 8.5\%), Gyeongnam (476 trees, 6.5\%) and Jeonbuk (446 trees, 6.1\%). There were also 207 trees found in Gangwon (2.8\%), 106 trees in Daegu (1.5\%), 103 trees in Seoul (1.4\%) and 92 trees in Daejeon (1.3\%; Fig. 2). Interestingly, there was no protected tree designated in Jeju except only one natural monument. Considering this tendency, it seems that Zelkova serrata trees are generally distributed across the country except Jeju, despite slight differences between regions, and that 


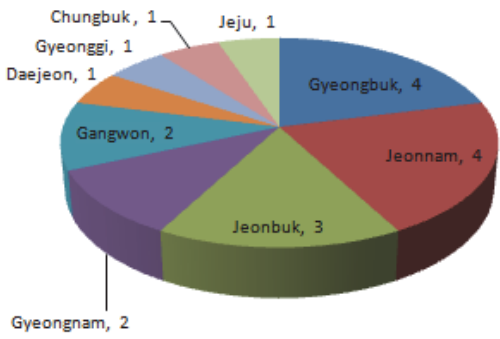

(A) Zelkova tree

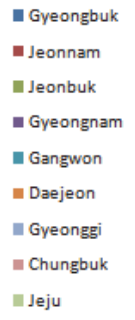

Ieju

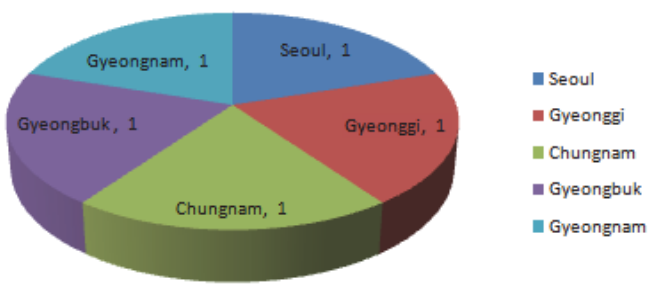

(B) Pagoda tree

Fig. 1. Regional distribution of Goemok as natural monuments (unit: tree).

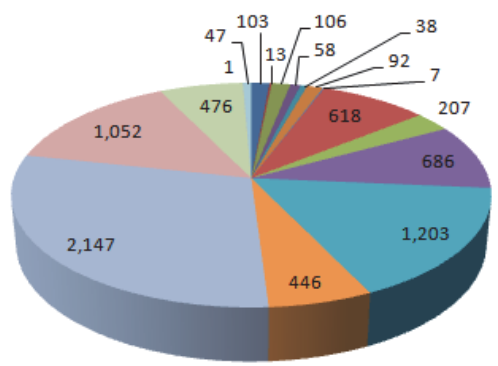

(A) Zelkova tree

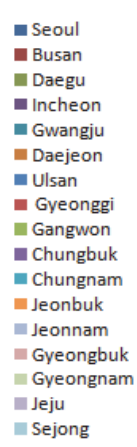

Jeju

Fig. 2. Regional distribution of Goemok as natural monuments or protected trees.

Zelkova serrata highly likely grows into an old big tree.

While protected Zelkova serrata trees were relatively evenly distributed across the country, the distribution of Sophora japonica trees showed slightly big deviations (Fig. 3). Out of a total of 377 Sophora japonica trees designated as a natural monument and a protected tree, the number of those found in Gyeongbuk was 187, showing an overwhelmingly high remaining rate $(49.6 \%)$, followed by Gyeonggi (37 trees, 9.8\%), Jeonnam (30 trees, 8.0\%), Chungnam (26 trees, 6.9\%), Daegu (23 trees, 6.1\%), Seoul (19 trees, 5.0\%), Gyeongnam (17 trees, 4.5\%), Ulsan and Chungbuk ( 7 trees, 1.9\% respectively), Incheon ( 6 trees, $1.6 \%$ ) and Busan and Jeonbuk (5 trees, 1.3\% respectively). The distribution rate of other regions including Gwangju, Dajeon, Gangwon, Jeju and Sejong was less than 1\%, showing a very low distribution rate. In jeju, only one tree $(0.3 \%)$ grew into an old big tree, which indicates that Sophora japonica, similar to Zelkova serrata, hardly grows into an old big tree. In particular, in the Daegu and Gyeongbuk regions where the Yeongnam Confucianism was actively practiced, a total of 209 Sophora japonica

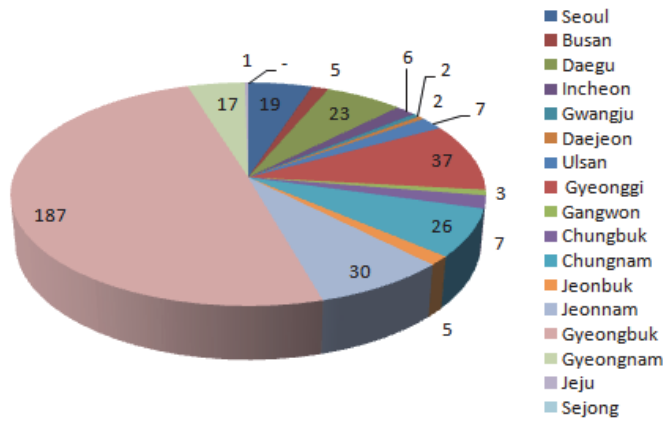

(B) Pagoda tree

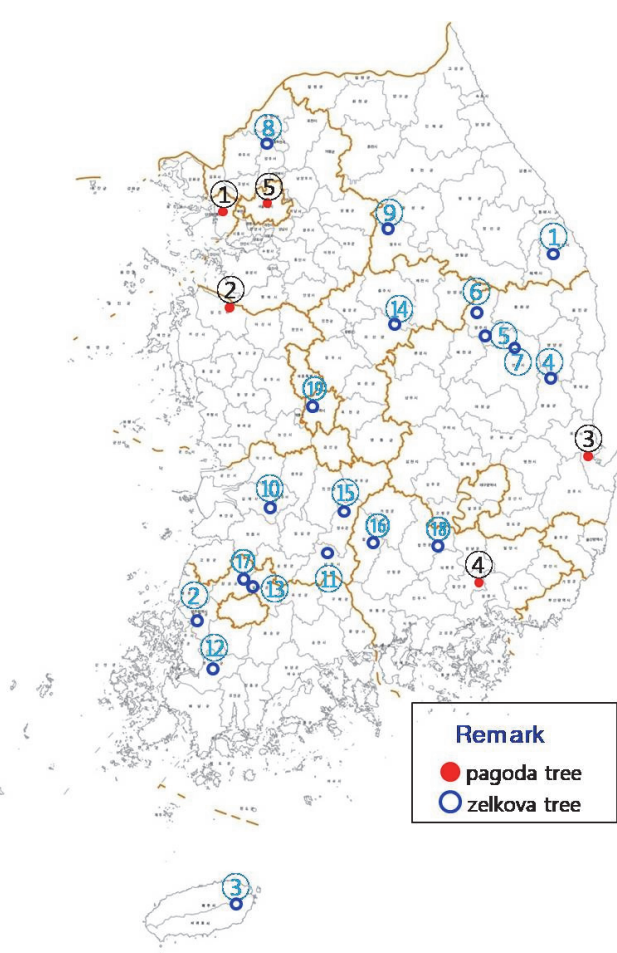

Fig. 3. Detailed map of natural monument Pagoda and Zelkova trees. Numbers represent cumulative frequency of each species. 


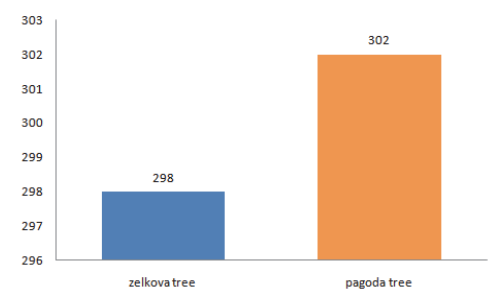

(A) Tree age

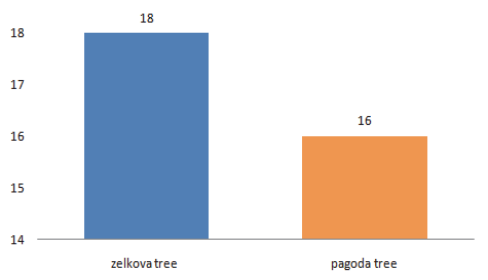

(B) Height

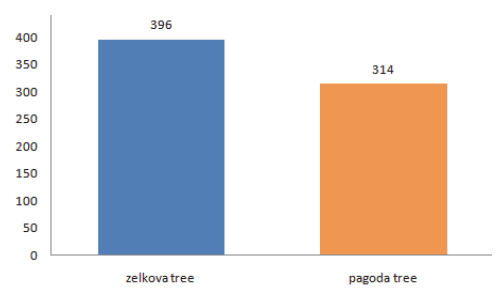

(C) Diameter at breast height (DBH)

Fig. 4. Comparison of tree size and age of Zelkova and Pagoda trees.

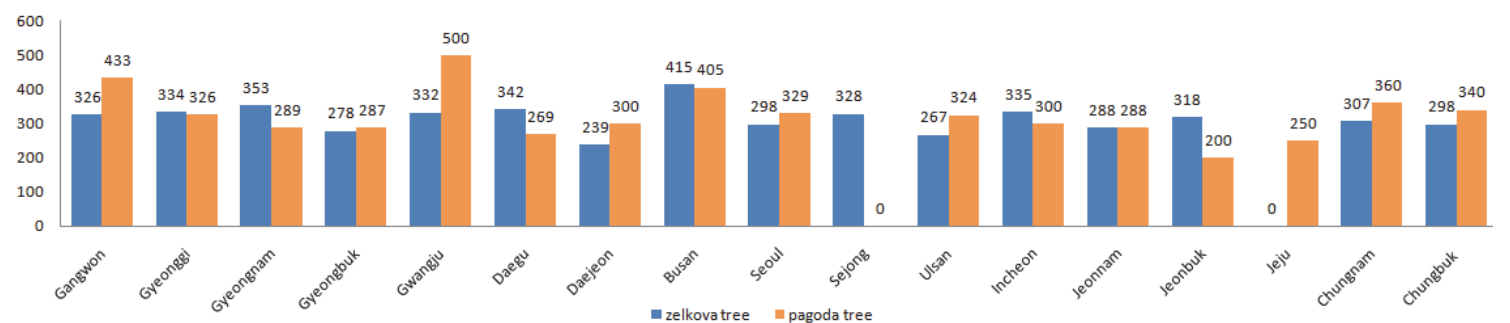

Fig. 5. Comparison of tree age on the Zelkova trees and Pagoda trees by region.

trees $(63.9 \%)$, unlike Zelkova serrata trees, remained as an old big tree, which is a very noticeable phenomenon. Especially in Andong, Gyeongbuk called the capital of Korea's moral culture, 11 Sophora japonica trees were designated as a protected tree, which is also a very interesting finding. Unlike Zelkova serrata trees, the survival of old big Sophora japonica trees was relatively very high in the Yeongnam region where the Yeongnam Confucianism was practiced, which was not a coincidence, and it is also difficult to interpret the result based on its flora only.

\section{Comparison of the age and size of Sophora japonica and Zelkova serrata trees}

The age of Sophora japonica and Zelkova serrata trees designated as a protected tree was compared, and as shown in Fig. 4, the average age of Zelkova serrata trees was 298, lower than that of Sophora japonica trees (302). Meanwhile, the average height of Zelkova serrata trees was $18 \mathrm{~m}$, relatively taller than that of Sophora japonica trees $(16 \mathrm{~m})$. In addition, the diameter at breast height was also surveyed, and that of Zelkova serrata and Sophora japonica trees was $396 \mathrm{~cm}$ and $314 \mathrm{~cm}$ respectively, which again indicates that Zelkova serrata trees were relatively bigger than Sophora japonica trees. These results show that Zelkova serrata trees can grow into a big tree com- pared to Sophora japonica trees, but it does not necessarily mean that they can live relatively longer as an old tree.

The age of Sophora japonica and Zelkova serrata trees was compared by region, and as shown in Fig. 5, the age of Zelkova serrata trees was relatively higher in regions including Gyeonggi, Gyeongnam, Daegu, Busan, Incheon and Jeonbuk, but the age of Sophora japonica trees was higher in other regions, showing no consistent tendency between region and age. Meanwhile, the height of trees was analyzed by region, and as shown in Fig. 6, that of Zelkova serrata trees was higher than that of Sophora japonica trees in all the surveyed regions except Daejeon. In addition, as shown in Fig. 7, the diameter at breast height in different regions was compared and that of Zelkova serrata trees was higher than that of Sophora japonica trees in all the surveyed regions except Gyeonggi, Busan and Seoul. Therefore, as assumed above, since Sophora japonica is not native, its environmental adaptability is lower than that of Zelkova serrata, and thus it seems to be highly likely that Sophora japonica trees withered to death even before they reached their maximum age.

Based on these results, the above mentioned assumption - the share of Zelkova serrata is relatively very high as its ratio to Sophora japonica was 53.3 : 2.7 - was reviewed. First, the assumption that Zelkova serrata trees are more likely to grow into an old big tree compared to 


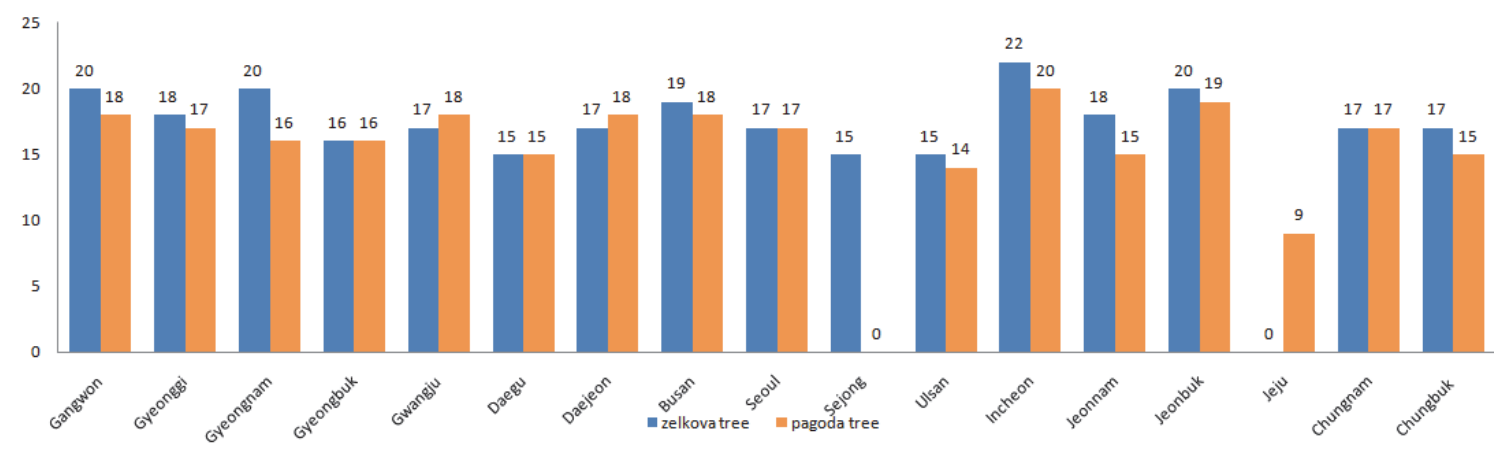

Fig. 6. Comparison of tree height on the Zelkova trees and Pagoda trees by region.

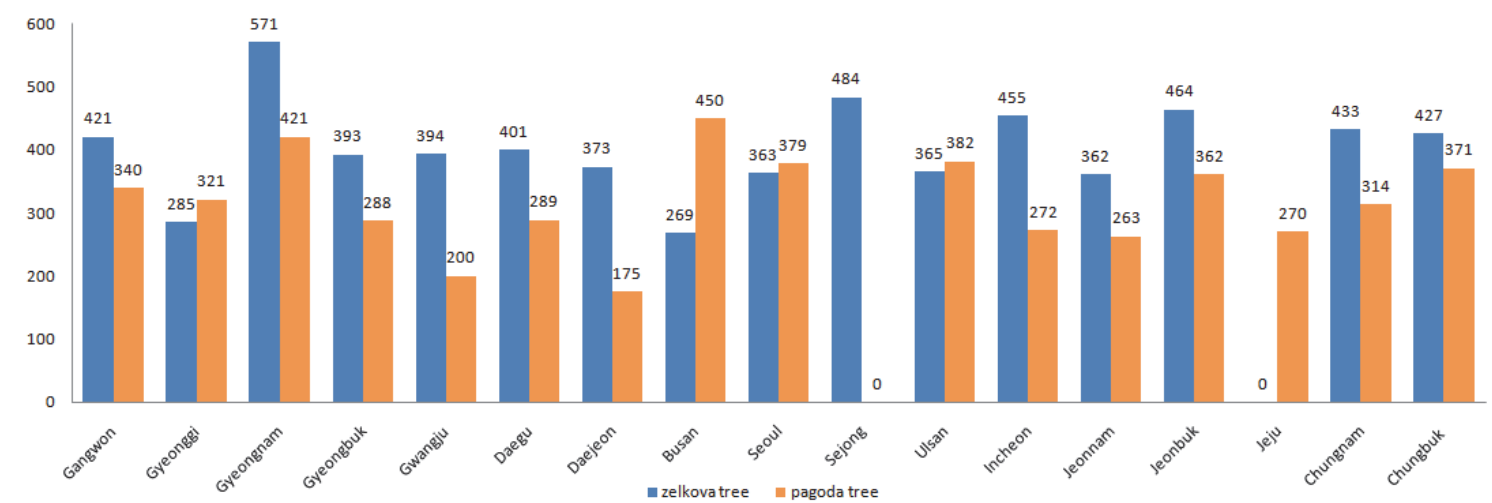

Fig. 7. Comparison of DBH on the Zelkova trees and Pagoda trees by region.

Sophora japonica trees was confirmed by the status of remaining old big trees. Second, the explanation - since Sophora japonica is not native, its environmental adaptability is low, and thus Sophora japonica trees withered to death before they reached their maximum age - was not accepted. Third, from the perspective of availability, the explanation - it is easier to access Zelkova serrata, a native species, than Sophora japonica, an introduced species - cannot be confirmed based on the results of this study only, but it seemed to be reasonable in the Joseon period.

\section{Conclusion}

The status of Sophora japonica and Zelkova serrata trees that are called 'Goemok' and are designated as a protected tree was surveyed to identify their remaining characteristics and to accumulate data that can be used to infer grounds for acculturation between them and the results were as follows:

1. A total of 5 cases (1.12\%) of Sophora japonica trees were designated as a natural monument and a total of 19 cases (4.27\%) of Zelkova serrata trees were designated as a natural monument. Except 1 Sophora japonica case and 3 Zelkova serrata cases, all the rest cases designated a single tree as a protected tree. The ratio of Zelkova serrata trees to Sophora japonica trees designated as a protected tree was 53.3 : 2.7, showing that the share of Zelkova serrata trees was relatively very high, which can be mainly attributed to the possibility that it can grow into an old big tree, environmental adaptability and availability.

2. Out of 7,281 Zelkova serrata trees designated as a protected tree, the number of Zelkova serrata trees found in Jeonnam was the highest (2,147 trees, 29.4\%), followed by Chungnam (16.5\%) and Gyeongbuk (14.4\%). Except one natural monument in Jeju, there was no Zelkova serrata tree designated as a protected tree. This tendency seems to be related to the fact 
that Zelkova serrata trees are highly likely to survive as an old big tree in most regions except Jeju.

3. Out of 321 Sophora japonica trees, a total of 210 Sophora japonica trees survived in Gyeongbuk and Daegue (55.7\%), which is a very high survival rate. In particular, in Andong, Gyeongbuk called the capital of Korea's moral culture, 11 Sophora japonica trees were designated as a protected tree, which is an interesting finding.

4. The overwhelmingly high survival rate of old big Sophora japonica trees in the Yeongnam region where Confucianism was actively practiced compared to that of Zelkova serrata trees is not a coincidence, and it is also difficult to interpret the result based on its flora only.

5. The age of protected Sophora japonica and Zelkova serrata trees was compared and the average age of Zelkova serrata trees was 298, lower than that of Sophora japonica trees (302). Its average height was $18 \mathrm{~m}$. taller than that of Sophora japonica trees $(16 \mathrm{~m})$, and its average diameter at breast height $(398 \mathrm{~cm})$ was also longer than that of Sophora japonica trees $(314 \mathrm{~cm})$, showing that Zelkova serrata trees were relatively bigger. Based on these results, therefore, it can be assumed that the growth potential of Zelkova serrata trees is higher than that of Sophora japonica trees, and that its potential to grow into an big tree is higher, but the explanation that Zelkova serrata trees can live long as an old tree is not completely valid.

\section{References}

Berry, J.W. 1997. Immigration, acculturation, and adaptation. Appl. Psychol. 46(1):5-34. https://doi.org/10.1111/j.146 4-0597.1997.tb01087.x

Choi, Y.H. 2013. Intercultural communication. Seoul, Korea: Sotong Publishing.

Han, S.Y. 2019. A study on the Guŭmok acculturation through the tree remaining Gujjeong. Doctoral dissertation, Woosuk University, Wanju, Korea.

Han, S.Y. and J.H. Rho. 2019. A study on the cultural changes of the trees in the trees remaining in Goijeong. Proceedings of Korean Society of Traditional Landscape Architecture 2019 Spring Conference(pp.102-106).

Huh, G. 2002. Gardens in Korea, the world where old Korean scholars wandered. Seoul, Korea: Daleunsesang Press.

Kang, P.K. 2014. Recognition of Arbores and Ge-I in China and Korea: Focusing on the apricot tree and ginkgo. The CHUNG KUK HAK PO 70:345-364.

Kang, P.K. 2015. The recognition on trees and culture transformation in China and Korea: Focusing on sophora and zelkova tree. DAEGU SAHAK 118:113-142. https://doi.org/10.17751/DHR.118.113

Kim, J.W. 2013. Encyclopedia of Korean plant ecology 1. Seoul, Korea: Nature and Ecology.

Lee, C.B. 1986. The new dendrology (pp. 161-163). Seoul, Korea: Hyangmunsa Press.

National Institute of Korean Language. 2000. Standard Korean language dictionary.

Rho, J.H., S.Y. Han, and S.H. Choi. 2019. A study on the acculturation of Guimok plantings through the remaining species of Guǐjeong. J. Korean Inst. Tradit. Landsc. Archit. 37(4):81-97. 